\title{
Influence of Rural Financial Development on the Agricultural Science and Technology Development
}

\author{
WU Tian ${ }^{1, a}$ \\ ${ }^{1}$ School of Finance, Xi'an Eurasia University \\ Xi'an, Shanxi 710065,China \\ awutian@eurasia.edu
}

Keywords: rural financial development, influence, agricultural science and technology development

\begin{abstract}
.he rural financial development and agricultural science and technology development as the two engines of rural economic development play an important role in promoting the farmers' income growth. To continue to increase farmers' income, to help farmers get rid of poverty and to become rich, we must pay more attention to the process of agricultural modernization development of agricultural science and technology development, continuously provide farmers with applicable and efficient agricultural skills. The innovation and transformation of agricultural science and technology need great support from rural financial system. Xiao and other scholars draw a conclusion that the rural financial development has good effects on the development of agricultural science and technology by using provincial panel data of the relationship of the structure of the rural financial development, the scale and efficiency of agricultural science and technology development in China .
\end{abstract}

\section{Introduction}

Services provided by a sound rural financial system has a significant promoting effect on agricultural science and technology development. The rural financial development promotes the farmers' income by promoting agricultural science and technology innovation. At present the rural financial theory is mainly divided into the following three types.

First, the main idea is based on the theory of subsidies and agricultural credit: the theory thinks that rural economic subject credit relies mainly on the high interest rates of informal financial institutions because developing countries have the problems of rural financial institutions and lack of credit system, so the rural financial should supply credit policy as the first strategy, mainly to solve the rural economy main body credit demand and should pay special attention to the credit supply and demand of rural poverty.

The second one is the theory of rural financial market; in fact, the rural residents have the need of savings, so agricultural credit subsidies is questionable assumptions of the theory of itself. After the theory of rural credit subsidies, with the universal countries' acceptance of market economy, rural financial market theory gradually becomes the main theory to guide the rural financial development. Third, another is the imperfect competition market idea; in the end of the 20th century, in the process of economic marketization, Latin America and Asia and other countries appear turmoil, the debt crisis and so on, which alerts people the limitation of "invisible hand" needing the government, the "visible hand", to stabilize financial markets via appropriate intervention. 


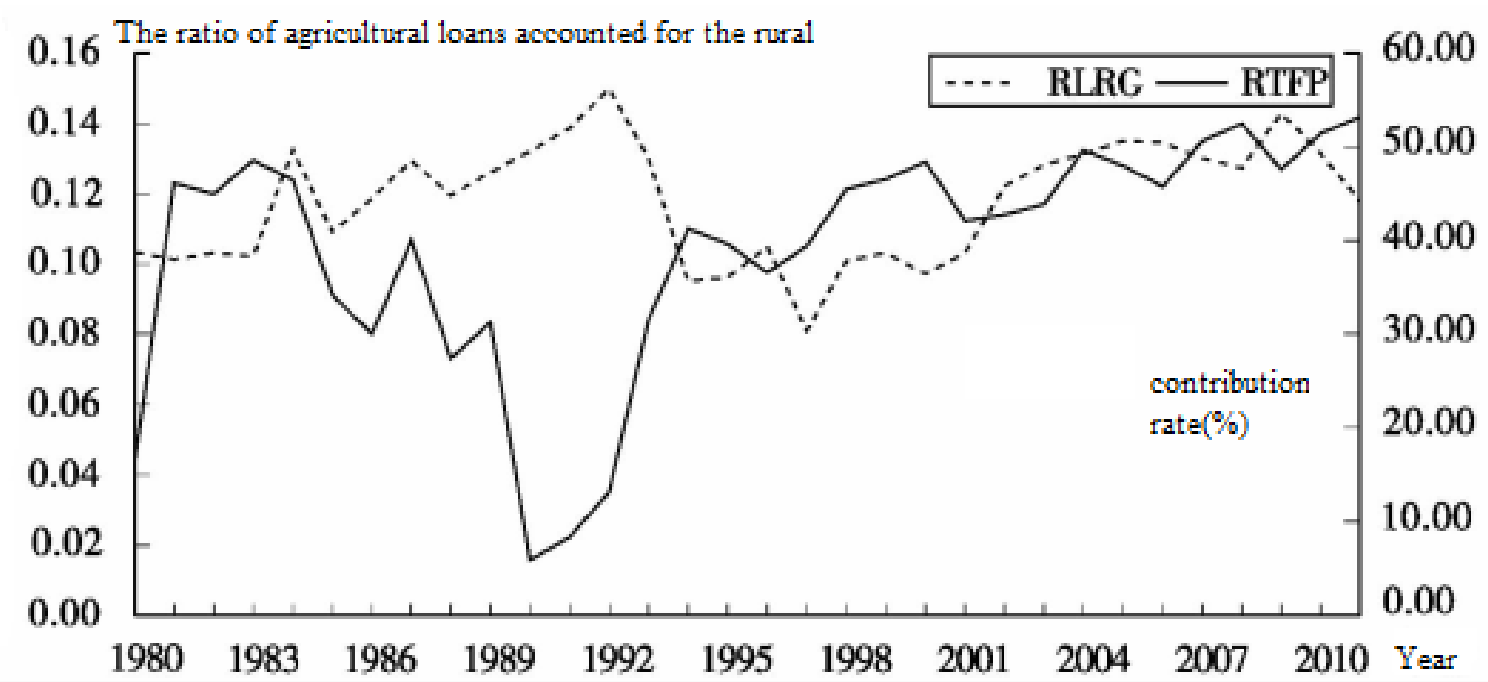

Chart 1: RLRG and PTFP

RTFP is used to measure the agricultural science and technology development. Agricultural science and technology development contribution rate is commonly used in the current research to measure the agricultural science and technology development. The indexes calculates generalized agricultural scientific and technological development's contribution to the growth rate of agricultural output share, including both natural science and technology development contribution, as well as the national policy, agricultural management and services such as social science and technology development contribution.

\section{The analysis of the contribution rate of rural financial development to the agricultural science and technology development}

Science and technology is the first productivity, the development of science and technology on has the huge influence on the development of the development of agricultural production. Agriculture as the foundation of the national economy plays an extremely important role in economic and social development and development of agricultural science and technology development also has pay great attention of scholars and attention.

The development of agricultural science and technology not only includes the development of agricultural production technology, agricultural production, management, management of technology improvement; but also the natural development of science and technology, social development of science and technology. The influence mechanism of contribution rate of rural financial development of agricultural science and technology is mainly manifested in three aspects: the rural financial development restricting independent innovation ability of agricultural science and technology, restricting achievements and application level of agricultural transformation of scientific and technological, restricting farmers' quality of science and technology, science and technology application ability, which directly affects the agricultural science and technology development contribution rate of ascension. In particular, it is reflected in the following three points:

First, the rural financial development restricts agricultural science and technology independent innovation ability promotion, affects the improvement of agricultural science and technology development contribution rate. Agricultural science and technology independent innovation ability has three aspects of meaning namely agricultural science and technology original innovation, integrated innovation ability and re-innovation ability on the basis of introduction of digestion. 


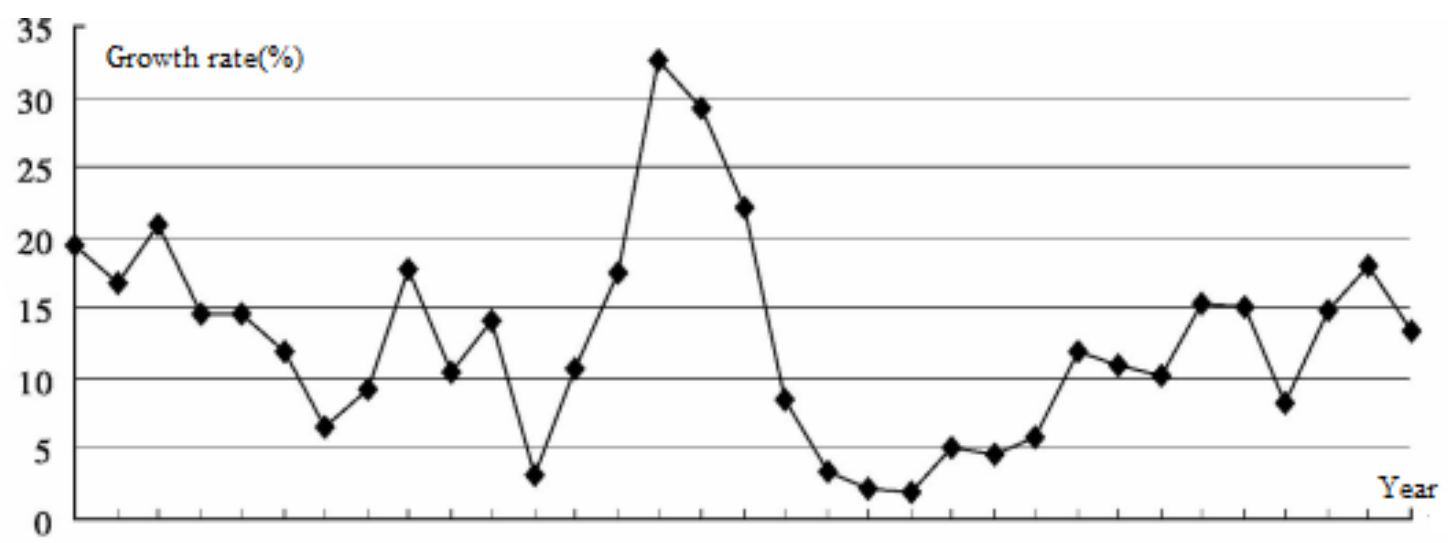

19801982198419861988199019921994199619982000200220042006200820102012

Chart 2: the growth rate of the farmers' income

Second, the rural financial development restricts agricultural transformation of scientific and technological achievements and application level of ascension, and affects the improvement of agricultural science and technology development contribution rate. Transformation of agricultural scientific and technological achievements and application is a complex work, which not only closely is related to the level of agricultural science and technology achievement itself, also with the conversion and extension the main body of agricultural science and technology achievements is closely linked. Application of agricultural science and technology achievements developed economic regions financing needs are more likely to get satisfaction, popularizing agricultural transformation of scientific and technological achievements and application level is relatively high, agricultural science and technology development contribution rate is high.

Third, the rural financial development restricts farmers' quality of science and technology and the improvement of science and technology application ability, affects the improvement of agricultural science and technology development contribution rate. Rural areas with high level of financial development, the government will have adequate financial resources to input the corresponding technology to improve farmers' quality of science and technology ability. The science and technology quality of farmer science and technology application ability are relatively high, the agricultural science and technology development contribution rate is high.

\section{The influence of contribution rate of agricultural science and technology development on the rural financial development}

The rural financial development will significantly have impact on agricultural science and technology development. The higher the rural financial development level is, the higher of the contribution rate of the agricultural science and technology development is. On the other hand, contribution rate of the agricultural science and technology development will be lower.

\subsection{The setting of the econometric model}

$$
\left\{\begin{array}{l}
\operatorname{RPNI}_{t}=\alpha_{1,0}+\sum_{i=1}^{k} \beta_{11, i} \operatorname{RPNI}_{t-i}+\sum_{i=1}^{k} \beta_{12, i} R_{L R G_{t-i}}+\sum_{i=1}^{k} \beta_{13, i} \operatorname{RTFP}_{t-i}+\varepsilon_{1, t} \\
\operatorname{RLRG}_{t}=\alpha_{2,0}+\sum_{i=1}^{k} \beta_{11, i} \operatorname{RPNI}_{t-i}+\sum_{i=1}^{k} \beta_{12, i} R^{k} R G_{t-i}+\sum_{i=1}^{k} \beta_{13, i} \operatorname{RTFP}_{t-i}+\varepsilon_{2, t} \\
\operatorname{RTFP}_{t}=\alpha_{3,0}+\sum_{i=1}^{k} \beta_{11, i} \operatorname{RPNI}_{t-i}+\sum_{i=1}^{k} \beta_{12, i} \operatorname{RLRG}_{t-i}+\sum_{i=1}^{k} \beta_{13, i} \operatorname{RTFP}_{t-i}+\varepsilon_{3, t}
\end{array}\right.
$$


For non-stationary time series but have co-integration relationship between variables, the vector autoregressive (VAR) model is more reliable than the traditional measuring method in the analysis of the conclusions.

$$
R P N I=\frac{A}{T}
$$

$A=$ the pure income increase of the farmers in the same year

$\mathrm{T}=$ the total income of the earlier year

RPNI represents the farmers' income growth indexes, adopting the most common used measure by the domestic scholars, the growth rate of per capital net income of farmers. The per capital net income of rural households refers to the total income of rural households that get from various sources accordingly to deduct the fee income after spending combined, including salary income, income of household operation, and property income and transfer income and so on.

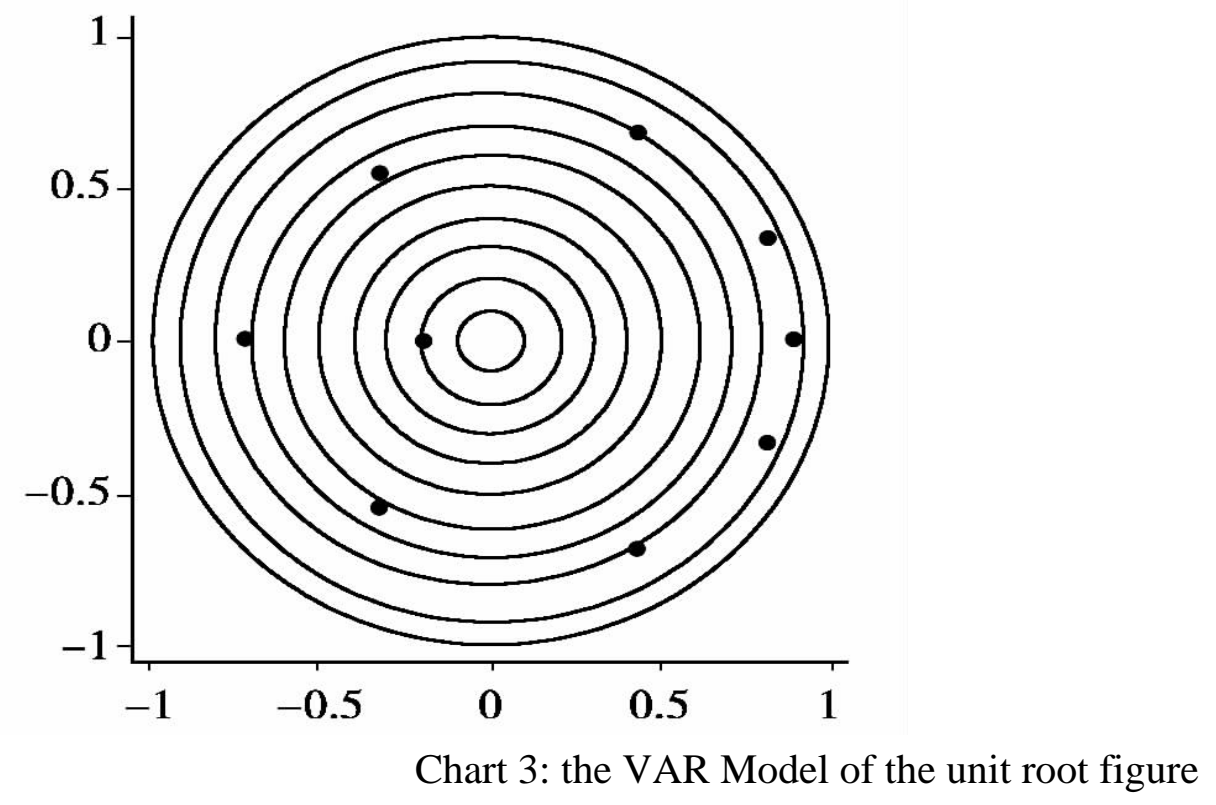

\subsection{The chosen of the variables}

Contribution rate index of agricultural science and technology development; from the existing literature data, among the quantitative methods to calculate the contribution rate of scientific and technological development to economic growth, the most used is the Cobb-Douglas production function and Solow (Solow residual method. Zhu Xigang, the first person to use Solow residual method to calculate the contribution rate of scientific and technological development. In 1997, the Ministry of Agriculture issued "about specification of methods of agricultural science and technology development contribution rate notification”, which set Zhu Xigang's calculation method as the national standards calculating the contribution rate of agricultural technology development.

At the beginning of the 20th century, XiongPeter, and Danisen and other scholars had theoretically proved that the financial development affect the role of science and technology development, XiongPeter emphasized that financial development promoting economic development by promoting innovation of science and technology in the research of the function of financial development on economic growth. He thought that the services provided by a sound financial system played an important role in technology innovation, the development of the financial sector had positive effects on economic growth. Levine put forward the idea that the more advanced of the financial system, the less of the cost of financial institutions used to evaluate science and technology innovation.

The key to solve the problem of rural agricultural science and technology development is the 
innovation and transformation of agricultural science and technology, which also needs support of rural financial system. In the agricultural scientific and technological development, we can not rely too much on farmers' themselves to ease financial constraints, but through the rural financial deepening to accelerate the development of agricultural science and technology. The rural financial reform should be guided by agricultural science and technology development to achieve the optimal allocation of rural financial resources, improve the efficiency of agricultural science and technology level.

\section{Summary}

Since China's reform and opening up, agricultural science and technology development is promoting transformation from the traditional extensive mode of agricultural production to the modern, efficient and sustainable agricultural production mode, in order to ensure national food security, promote agricultural production, increase farmers' income and rural prosperity. In the factors influencing the agricultural scientific and technological development, the support of rural finance is very outstanding. Scattered rural financial system affects the performance of agricultural science and technology innovation, will affect the level of contribution rate of agricultural science and technology development through mobilizing savings, scientific and technological innovation risk and improving the efficiency of resource allocation.

\section{Acknowledgements}

The Project Supported by the Social science foundation of Shaanxi Province in 2014 (Program No. 2014D42)

Study on Optimization of Counties’ Rural Financially Ecological System in Shaanxi Province The Project Supported by Natural Science Basic Research Plan in Shaanxi Province of China in 2016 (Program No.2016JM7007)

Research on "Financial Valley " Mode and Orderly Mechanism of Scientific and Technological Finance of Shaanxi Province

\section{References}

[1] Granger Clive. Some Recent Developments in a Concept of Causality. Journal of Econometrics, 1988( 39) : 199 -211.

[2] Idachaba, F. S. Policy Research In Agriculture: The View of A Policy Analyst. In National Agricultural Research In Development Cooperation: The Role of Research In Agricultural Policy Making in Sub-Saharan Africa. Bonn, Germany: BMZ /GTZ /CTA/ATSAF, 1998, 61-87.

[3] Toch M. Agricultural development and agricultural technology in medieval Germany: An alternative model. Technology and Resource Use in Medieval Europe: Cathedrals, Mills, and Mines, 1997,(15): 158 -169.

[4] Chieochan, Factors affecting the use of information technology in Thai agricultural cooperatives: a work in development. Electronic Journal on Information Systems in Developing Countries, 2000, ( 2) : 158-163.

[5] Dolla, Agricultural science and technology in China: A review of three decades of policy and development. Journal of Science and Technology Policy in China,2011,2( 1) : 79-93. 